\title{
Potential Consequences of Hosting an Ant-tended Treehopper, Publilia concava, for Tall Goldenrod, Solidago altissima
}

\author{
Luke J. McCartin*, Nabil A. Nasseri, \& Alison K. Brody \\ Department of Biology, University of Vermont, Burlington, VT \\ bttps:/ / doi.org/10.33697/ / ajur.2019.002 \\ Student:lukejmccartin@gmail.com* \\ Mentors:nnasseri@gmail.com,Alison.Brody@uvm.edu
}

\begin{abstract}
In ant-hemipteran mutualisms, 'tending' ants indiscriminately defend hemipterans from other arthropods, protecting mutualismhosting plants from defoliating herbivores in some cases. Censuses of a treehopper, Publilia concava, observations of tending ants, and measurements of leaf area were conducted on tall goldenrod, Solidago altissima, over the course of a summer at a field site in central Vermont. Hosting ant-tended treehopper aggregations had no effect on leaf area or the ability for goldenrod to flower, suggesting that in the absence of an herbivore outbreak this mutualism is neither necessary nor inherently detrimental for goldenrod. These findings support the hypothesis that the net consequence of the ant-hemipteran mutualism for its host plant depends on the costs of hemipteran damage, and the benefits of ant defense from other arthropods.
\end{abstract}

\section{KEY WORDS}

Ants; Mutualism; Ant-plant Interactions; Treehopper; Hemiptera; Ant-hemipteran Mutualism

\section{INTRODUCTION}

The consequences of mutualisms for their participants are highly variable and governed by the ecological context in which they occur. ${ }^{1}$ In an ant-hemipteran mutualism (AHM), 'tending' ants defend hemipterans from natural enemies in exchange for honeydew excretions, which they consume as a food resource. ${ }^{2}$ Variability in the consequences of an AHM for its hemipteran participants is well known. ${ }^{3,4}$ For instance, the survivorship of a treehopper, Publilia concava, inversely relates to the size of its aggregation and the distance of its host plant, tall goldenrod, Solidago altissima, from tending ant colonies. ${ }^{5}$

However, AHMs are less studied with regard to variability in the impacts that they may have on their host plants. While indiscriminate antagonism by tending ants may deter other herbivores, such a benefit must outweigh the inherent cost of hosting hemipteran aggregations. ${ }^{6}$ Therefore, an AHM may be most beneficial for its host plant when the abundance of other, nonhoneydew producing, herbivores is high. ${ }^{7}$ Notably, when the density of herbivorous caterpillars was high, AHM-hosting cotton plants produced a greater percent more bolls than non-host plants than when caterpillar density was low. ${ }^{8}$

Messina (1981) reported that two species of chrysomelid beetles, Trirhabda spp., occur in high enough densities to completely defoliate tall goldenrod. ${ }^{9}$ Under such conditions, tall goldenrod that hosted $P$. concava aggregations most consistently tended by ants were protected from defoliation, grew taller, and were most likely to flower. ${ }^{9}$ However, hosting large treehopper aggregations comes at an inherent cost to goldenrod. P. concava pierce the midribs of goldenrod leaves and consume phloem sap, potentially lowering the ability for AHM-hosting ramets to photosynthesize. ${ }^{9}$ This study examined the potential benefits and detriments for goldenrod hosting an AHM in the absence of an outbreak of Trirbabda spp. or similar herbivores. Under such circumstances it can be hypothesized that either there is either no benefit to goldenrod that host an AHM, or that the inherent cost of hosting treehopper large aggregations incurs a net-negative consequence.

\section{METHODS}

From June through October 2016, a study was conducted at a field site in Jericho, Vermont (44'27’42” N, 7259’38" W). The field site is an open field dominated by grasses and perennial herbs and bordered by a mixed deciduous forest along the east and open meadows to the north, south and west. Throughout the field site, $S$. altissima hosts $P$. concava aggregations that are tended by three species of ants: Formica subsericea, Camponotus noveboracensis, and a species of the genus Lasius, most likely Lasius alienus. Ants were identified according to Ellison et al. 2012.10

In early June, when $P$. concava adults had begun ovipositing on goldenrod, $52 \mathrm{~S}$. altissima ramets were marked haphazardly, with an attempt made to include a relatively equal number of ramets that were and were not selected by $P$. concava for oviposition. On 28 
June, nymphs had hatched, and from that date until September 12th, censuses were conducted on these ramets approximately weekly. During each census, treehopper adults and nymphs were counted systematically, working from the base of the stem upwards. In mid-September, three leaves nearest to the point three-quarters of the way up the stem from the base ${ }^{9}$ were collected from 30 randomly selected ramets: 15 that did host ant-tended treehopper aggregations and 15 that did not. Only 35 ramets from the largest patch of $S$. altissima encompassing an area of approximately $15 \mathrm{~m}^{2}$ were considered in the random selection in an effort to control for possible environmental variability among goldenrod patches at the field site. For this purpose, ramets were deemed as having hosted an aggregation if the number of $P$. concava adults and nymphs counted during any one census was greater than 50 , an arbitrary value above which most aggregations exceeded. The image editing software ImageJ was used to estimate total leaf area from each leaf (adapted from O'Neal 2002), ${ }^{11}$ and the 3 measurements from each ramet were averaged to obtain a single, average value. Towards the end of the flowering season in mid-October, the height of these 30 ramets was measured and their inflorescences were collected. Height was measured from the base of the stem to the highest point of the bouquet while gathering the inflorescence by hand.

\section{Statistical analysis}

Of the 30 ramets sampled for leaf area, we considered a ramet as having hosted $P$. concava if we counted at least 15 treehoppers on that ramet during any one census. 15 was used as a cutoff for the statistical analysis, rather than 50 , because in fact one ramet with a maximum count of 15 treehoppers had hosted a small $P$. concava aggregation. On ramets where the maximum count of treehoppers during any one census was lower than 15, $P$. concava presence was circumstantial and not due to oviposition and the establishment of an aggregation. Thus, the statistical analysis included $16 \mathrm{~S}$. altissima ramets that hosted ant-tended treehopper aggregations and 14 that did not. Average leaf area was treated as a response variable in an analysis of covariance (ANCOVA), with the main effect as treehopper aggregation presence. Height was treated as a covariate, because leaf area and height were positively correlated (Linear Regression, Adjusted $\mathrm{R}^{2}=0.1362, \mathrm{p}<0.05$ ). All analyses were conducted in $\mathrm{R}$ version $3.4 .4 .{ }^{13}$ using code from Mangiafico 2015. ${ }^{14}$ Figures 1 and 2 were created in R using the package 'ggplot2'.15

\section{RESULTS}

P. concava aggregations peaked in number during mid-July (Figure 1). The largest number of adults and nymphs recorded on any single S. altissima ramet during any one census was 502 individuals. Formica subsericea and Camponotus noveboracensis tended treehoppers on the same ramet concurrently, and Lasius sp. constructed fragile 'shelters', apparently made of soil, around the treehoppers they were tending. This behavior has been described before by Lasius alienus to protect lycaenid caterpillars, ${ }^{16}$ but to the authors' knowledge this is the first time that it has been reported to occur on tall goldenrod to protect $P$. concava. The presence of $P$. concava aggregations did not have a significant effect on leaf area (ANCOVA, $\mathrm{F}_{1,27}=0.3231, \mathrm{p}=0.57$; Figure 2), and all 30 ramets, AHM-hosting and non-hosting alike, produced inflorescences.

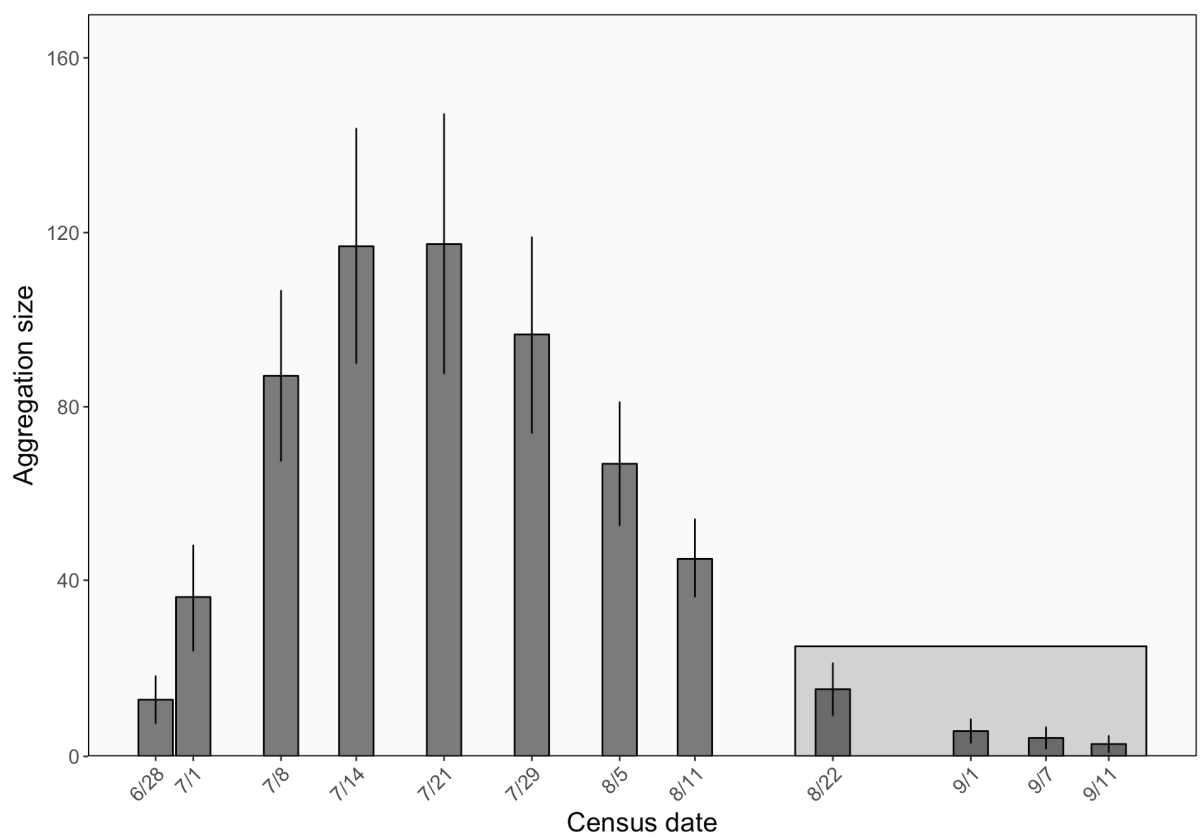

Figure 1. Mean aggregation sizes of $P$. concava treehoppers among 16 S. altissima ramets that hosted ant-tended aggregations during the summer of 2016. Censuses conducted when inflorescences were in bloom are in the highlighted box. Vertical lines represent standard error. 


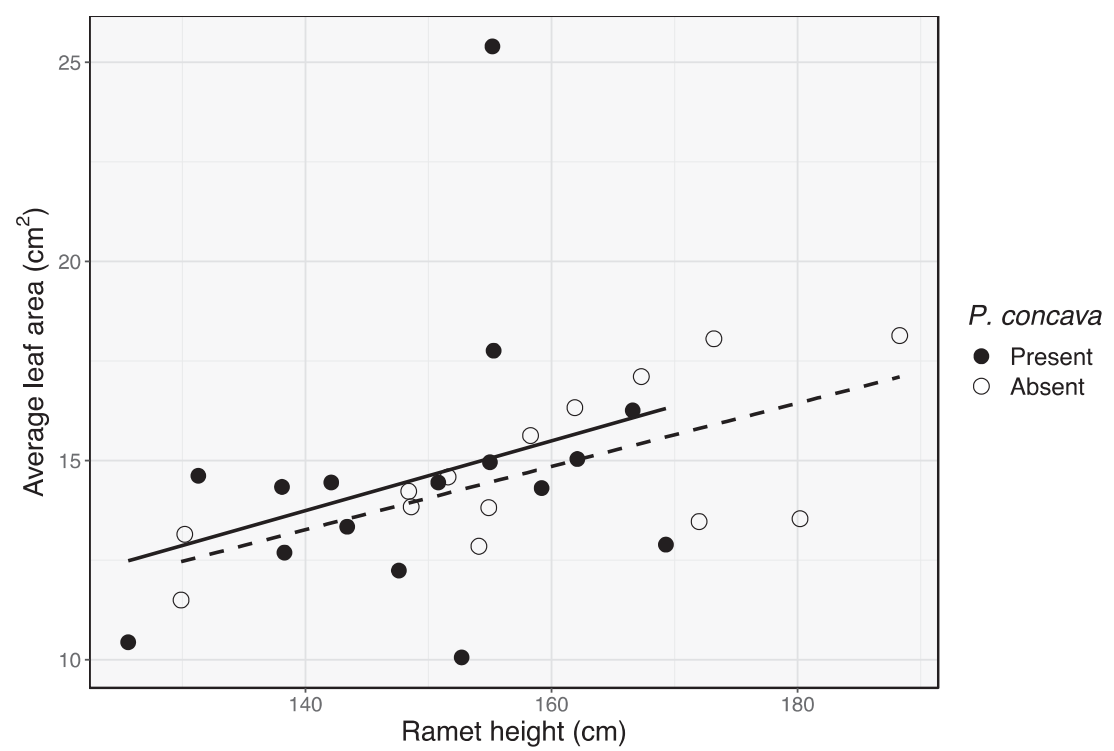

Figure 2. Relationship between the leaf area and height of $30 \mathrm{~S}$. altissima ramets with the plotted linear regression fits for ramets that that did (solid line) and did not (dashed line) host ant-tended $P$. concava treehopper aggregations.

\section{DISCUSSION}

Messina (1981) reported that under severe herbivory from leaf-chewing beetles, Trirhaba spp., goldenrod hosting P. concava aggregations most consistently tended by ants had the highest likelihood of flowering, and subsequently setting seed. ${ }^{9}$ In this study, goldenrod ramets were under little threat of severe defoliation and, indeed, there was no significant difference in leaf area between ramets that hosted AHM and those that did not. Under these circumstances, there was no evidence that the presence or absence of an AHM impacted the ability for goldenrod to flower. However, it is important to consider other key factors that may impact how the presence of $P$. concava influences the performance of goldenrod and present opportunities for further study.

On goldenrod ramets hosting treehopper aggregations, it was clear that feeding by $P$. concava damaged goldenrod leaves, causing them to droop at the site where they were initially pierced and brown more quickly than undamaged leaves (Figure 3). It would be useful to directly measure this damage to AHM-hosting ramets and its implications. The effects on photosynthetic rate by other goldenrod herbivores have been studied in a greenhouse setting, finding that only a spittlebug, Philaenus spumarius, significantly reduced the photosynthetic and growth rates of goldenrod. ${ }^{17}$ Among the insects examined in that study, which also included aphids and Trirhabda beetles, P. concava is most closely related to the spittlebug. A similar greenhouse study may find that when treehopper aggregations are extraordinarily large, they have a similar effect on AHM-hosting goldenrod that translates to a net-negative consequence for flowering success.

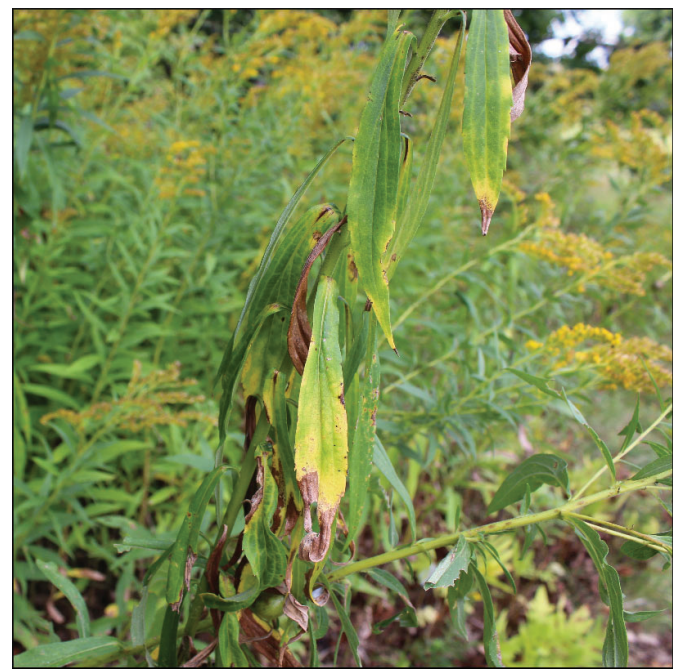

Figure 3. Aggregations of the treehopper, $P$. concava, damage the leaves of goldenrod hosts by piercing their midribs and consuming phloem. Damaged leaves droop at the site of feeding and brown more quickly than undamaged leaves. 
At the field site, the presence of $P$. concava may not be the most important insect affecting the overall performance of goldenrod. Upon inspection it became apparent that case-bearing moth larvae (Lepidoptera: Coleophoridae) had consumed seeds of goldenrod inflorescences. It would be intriguing to discern whether these seed predators or defoliation by Trirhabda spp. beetles has a greater effect on reproductive success, and if ultimately, hosting an AHM is of significant benefit to goldenrod in terms of relative fitness. It is also important to recognize that since $S$. altissima is clonal, it is possible that the ramets in this study represented a single clone, and that the ability for ramets to share resources may protect a clone from $P$. concava from extensive damage as a whole. ${ }^{18}$ A study incorporating genetic analyses and comparing the mutualism's impacts among separate patches of $S$. altissima over a larger spatial and temporal scale would be tedious, but reveal a more accurate and entire representation of the net effects of hosting an AHM for goldenrod.

\section{CONCLUSIONS}

Underscoring the importance of considering the ecological context in which mutualisms occur, this study considered the infrequently tested hypothesis ${ }^{6,8}$ that that the benefits of hosting an AHM may depend on factors such as the abundance of other herbivores. ${ }^{8}$ These findings suggest that examining the effects of an ant-tended treehopper on its host's photosynthesis, and further investigating the net effect of hosting an AHM in the context of herbivores other than defoliating beetles, such as lepidopteran seed predators, may prove useful in elucidating the conditions under which AHMs are beneficial as well as costly.

\section{ACKNOWLEDGEMENTS}

The authors thank Samantha Alger, Alex Burnham and Emily Mikucki for comments on an earlier draft of the manuscript. The authors also thank three anonymous reviewers and the editor, Dr. Bill Bromer, for insightful comments that improved the manuscript. This research was funded by the University of Vermont's Office of Undergraduate Research, through a Summer Undergraduate Research Fellowship awarded to LJM.

\section{REFERENCES}

1. Chamberlain, S. A., Bronstein, J. L., and Rudgers, J. A. (2014) How context dependent are species interactions?, Ecology Letters 17(7), 881-890.

2. Way, M. J. (1963) Mutualism between ants and honeydew-producing Homoptera, Annual Review of Entomology 8(1), 307-344.

3. Cushman, J. H., and Whitham, T. G. (1989) Conditional mutualism in a membracid-ant association: temporal, age-specific, and density-dependent effects, Ecology 70(4), 1040-1047.

4. Bronstein, J. L. (1994) Conditional outcomes in mutualistic interactions, Trends in Ecology \& Evolution 9(6), 214-217.

5. Morales, M.A. (2000) Mechanisms and density dependence of benefit in an ant-hemipteran mutualism, Ecology 81(2), 482-489.

6. Styrsky, J. D., and Eubanks, M. D. (2007) Ecological consequences of interactions between ants and honeydew-producing insects, Proceedings of the Royal Society of London B: Biological Sciences, 274(1607), 151-164.

7. Fritz, R. S. (1983) Ant Protection of a Host Plant's Defoliator: Consequence of an Ant-Membracid Mutualism, Ecology 64(4), 789-797.

8. Styrsky, J. D., and Eubanks, M. D. (2010) A facultative mutualism between aphids and an invasive ant increases plant reproduction, Ecological Entomology, 35(2), 190-199.

9. Messina, F. J. (1981) Plant protection as a consequence of an ant-membracid mutualism: interactions on goldenrod (Solidago sp.), Ecology 62(6), 1433-1440.

10. Ellison, A. M., Gotelli, N. J., Farnsworth, E. J., and Alpert, G. D. (2012) A field guide to the ants of New England. Yale University Press, New Haven, Connecticut, USA.

11. O'Neal, M. E., Landis, D. A., and Isaacs, R. (2002) An inexpensive, accurate method for measuring leaf area and defoliation through digital image analysis, Journal of Economic Entomology 95(6), 1190-1194.

12. Maddox, G. D., Cook, R. E., Wimberger, P. H., and Gardescu, S. (1989) Clone structure in four Solidago altissima (Asteraceae) populations: rhizome connections within genotypes, American Journal of Botany 76(2), 318-326.

13. R Core Team. (2018) R: A language and environment for statistical computing, R Foundation for Statistical Computing, Vienna, Austria. bttps:// wmw.R-project.org/.

14. Mangiafico, S.S. (2015) An R Companion for the Handbook of Biological Statistics, version 1.3.2.

15. Wickham, H. (2009) ggplot2: Elegant Graphics for Data Analysis. Springer-Verlag New York.

16. Fiedler, K., and Maschwitz, U. (1988) Functional analysis of the myrmecophilous relationships between ants (Hymenoptera: Formicidae) and lycaenids (Lepidoptera: Lycaenidae), Oecologia 75(2), 204-206.

17. Meyer, G. A., and Whitlow, T. H. (1992) Effects of leaf and sap feeding insects on photosynthetic rates of goldenrod, Oecologia $92(4), 480-489$.

18. Bazzaz, F. A., Chiariella, N. R., Coley, P. D., and Pitelka, L. F. (1987) Allocating resources to reproduction and defense, BioScience 37(1), 58-67. 


\section{ABOUT STUDENT AUTHORS}

Luke McCartin graduated from the University of Vermont in May 2017 with a Bachelor of Science in Biological Sciences.

Following graduation, he joined the Biology Department at the Woods Hole Oceanographic Institution as a research assistant, and he plans to pursue a graduate degree studying biology and conservation.

\section{PRESS SUMMARY}

Ants and treehoppers engage in a common mutualism when ants defend treehoppers from other insects in order to consume their sugar-rich honeydew excretions. This species interaction may be vital for goldenrod to flower in some instances, because ants indiscriminately attack many insects, including herbivorous beetles. We observed the mutualism on goldenrod at a field site in Vermont over the course of a summer, and consider the implications of hosting treehoppers for goldenrod in the absence of defoliating beetles or similar herbivores. 